\title{
Dynamic monitoring and analysis of alien invasive land plants in autumn and winter in Qionghai Lake
}

\author{
Lin $\mathrm{Bai}^{1, *}$, Kun $\mathrm{Yao}^{2}$, Yiying Yang ${ }^{3}$, Jiaying $\mathrm{Li}^{3}$, Qun $\mathrm{Zhao}^{3}$ \\ ${ }^{1}$ Lecturer, College of Resource and Environment, Xichang College, Xichang 615000, Sichuan, China \\ ${ }^{2}$ Teaching Assistant, College of Resource and Environment, Xichang College, Xichang 615000, Sichuan, China \\ ${ }^{3}$ Student, College of Resource and Environment, Xichang College, Xichang 615000, Sichuan, China
}

\begin{abstract}
Qionghai Lake is the second largest freshwater lake in Sichuan Province. Invasive plants have damaged the ecological balance of Qionghai Lake. Regular investigation and monitoring of invasive alien plants in Qionghai Lake in autumn and winter. Study structural changes and trend changes. Mapping dynamic monitoring of the distribution of invasive plants. Upon investigation, a wide range of invasive plants with a large rits are Eupatorium Adenophorum, Lantana camara,Bidens alba(L.) DC, Alternanthera philoxeroides, Pharbitis purpurea(L.) Voisgt and Oxalis corniculata L. The introduction of the Tagetes erecta $L$ as Ornamental plants, the proliferation occurred because of mismanagement. The number of Mirabilis jalapa L. is very small. Analysis of the way of invasive alien plants into the Qionghai Sea and the measures of prevention and control.
\end{abstract}

Qionghai Lake is located in Xichang, Liangshan Yi Autonomous Prefecture, Sichuan Province of China. It is a highland wetland nature reserve.Covers an area of about 30 square kilometers. Most of the tree species in the wetlands are imported species from the outside. The study of invasive plants in Qionghai Lake has long been dominated by its ecological influence. But less research on predicting its growth trend. Through a comparison of average extreme temperatures in the same period of previous years, it is found that 2018 was significantly higher than in previous years. The comfortable temperature helps some plants grow.

\section{Sample and survey route selection}

There are 45 species of invasive species from Qionghai Lake, which belong to 20 sections. According to the number and distribution range of invasive plants in this area, 8 varieties are selected, such as Eupatorium Adenophorum, Lantana camara, Bidens alba (L.) DC, Alternanthera philoxeroides, Pharbitis purpurea (L.) Voisgt, Oxalis corniculata L. Tagetes erecta L. Mirabilis jalapa L. and so on. The sampling time is October and December in 2018 .

Table 1. City Of Xichang Extreme temperature Summary form For December $\quad$ (2013-2018)

\begin{tabular}{|c|c|c|}
\hline & Max Temp $\left({ }^{\circ} \mathbf{C}\right)$ & Min Temp $\left({ }^{\circ} \mathbf{C}\right)$ \\
\hline 2013 & 14.55 & 3.65 \\
\hline 2014 & 15.23 & 4.61 \\
\hline
\end{tabular}

\begin{tabular}{|l|l|l|}
\hline 2015 & 16.19 & 5.26 \\
\hline 2016 & 17.94 & 6.35 \\
\hline 2017 & 17.06 & 5.13 \\
\hline 2018 & 19.9 & 4.84 \\
\hline
\end{tabular}

The survey route is Liangshan Vocational and Technical School, Qionghai Wetland Park, Moon Goddess Square, Qionghai Hotel, Jingfeng Specialty Barbecue Restaurant, Birdwatching Island. This route is a free wetland tour area. It has high traffic and high openness. Human factors are extremely susceptible to affectther spread of invasive plants.

\section{Data processing}

\subsection{Source of data}

Grid data source is geospatial data cloud Landsat 8 OLITIRS satellite digital products. Data identity is 1C81300412018051LGN00. The date is February 20, 2018. Stripe No. is 130 . The Line No. is 41 .Vector data sources are the spatial data coordinates of the eight invasive plants selected.

\subsection{Data ratings}

Preparation of a four-level diffusion risk warning scale as a criterion for predicting the risk of invasive alien plants. Level I is the highest level. The higher the grade, the larger the diameter of the alien invasive plant distribution. The

\footnotetext{
* Corresponding author: Lin Bai. E-mail addresses: 115172717@qq.com
} 
red, orange, yellow and blue of the alert indicates that the level of harm may be high to low.

Table 2. Alien invasive plant diffusion risk early warning level table

(m)

\begin{tabular}{|c|c|c|c|}
\hline $\begin{array}{l}\text { Diffusion } \\
\text { level }\end{array}$ & $\begin{array}{l}\text { Distribution } \\
\text { diameter }\end{array}$ & $\begin{array}{l}\text { Potential } \\
\text { risks }\end{array}$ & Alert level \\
\hline I & $>2000$ & Highest & Red \\
\hline II & $1000 \sim 2000$ & Higher & Orange \\
\hline III & $100 \sim 1000$ & Medium & Yellow \\
\hline IV & $<100$ & Low & Blue \\
\hline
\end{tabular}

\section{Results and analysis}

\subsection{Spatial distribution features}

Eupatorium Adenophorum along the inside of the road distribution is more and the plant was small. Oxalis corniculata $L$. is distributed on both sides of the road, and mostly under the stack road. Alternanthera philoxeroidesgrows in pieces nearby the lake. Pharbitis purpurea(L.) is found on the inside of the road near
Qionghai Park. Bidens alba(L.) DC needle grass distribution range is wide. Qionghai Park to Moon Goddess Square a mostly hardened floor. Plants grow in a smaller range and only a small number of invasive plants are found by the sea, such as upatorium Adenophorum,Bidens alba(L.) DC. Moon Goddess Square to Jingfeng specialty barbecue restaurant section due to road planning and human management, all kinds of invasive plants scattered. Lantana camara is introduced as an ornamental plant and spreads near the cultivated area. Eupatorium Adenophorum plants are higher and grow in clusters, because of the adequate light in Bird-watching island.

\subsection{Structural changes}

The first survey find that the most widely distributed of Pharbitis purpurea(L.) Voisgt, Eupatorium Adenophorum, Lantana camara and Alternanthera philoxeroides in invasive plants.Distribution diameter of approximately is 2039.29 meters. The distribution diameter of Oxalis corniculata L. and Bidens alba(L.) DC is about 1207.45 meters. The number of Tagetes erecta L. and Mirabilis jalapa $L$. is very small, with a distribution diameter of about 251 meters. The second investigation find that the Bidens alba(L.) DC have spread, with a distribution diameter of about 2154.34 meters.

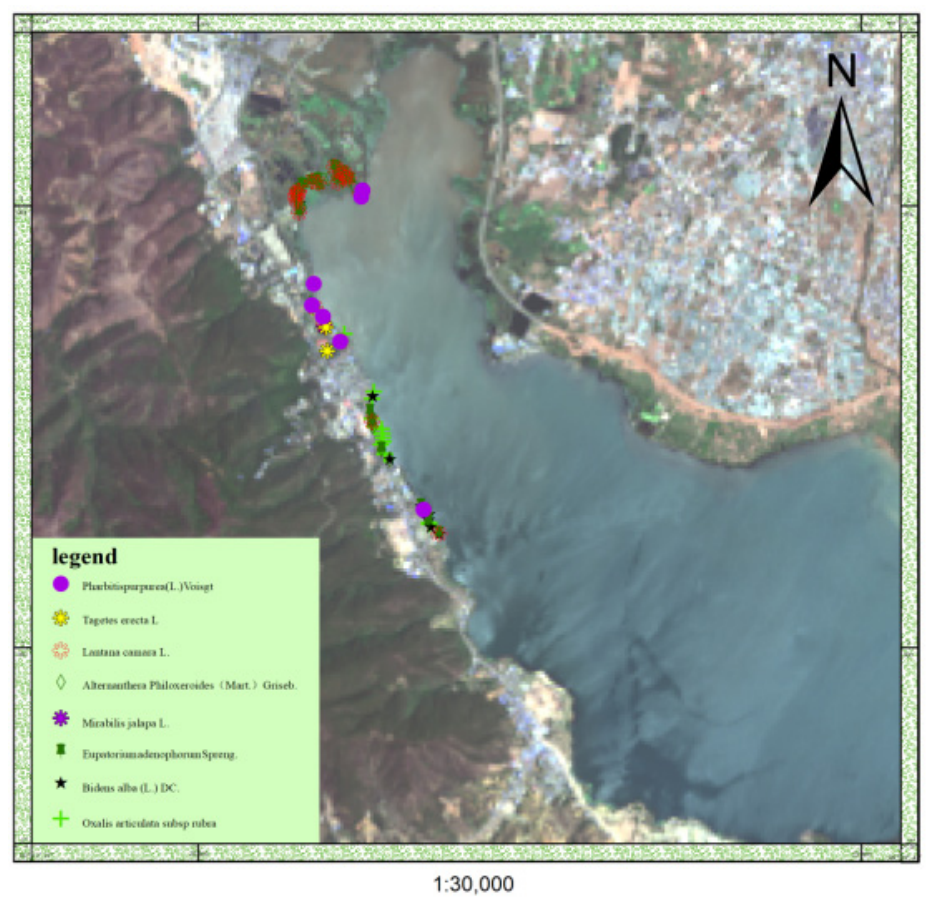

Fig.1. Map of the first investigation and distribution of invasive plants in Qionghai 


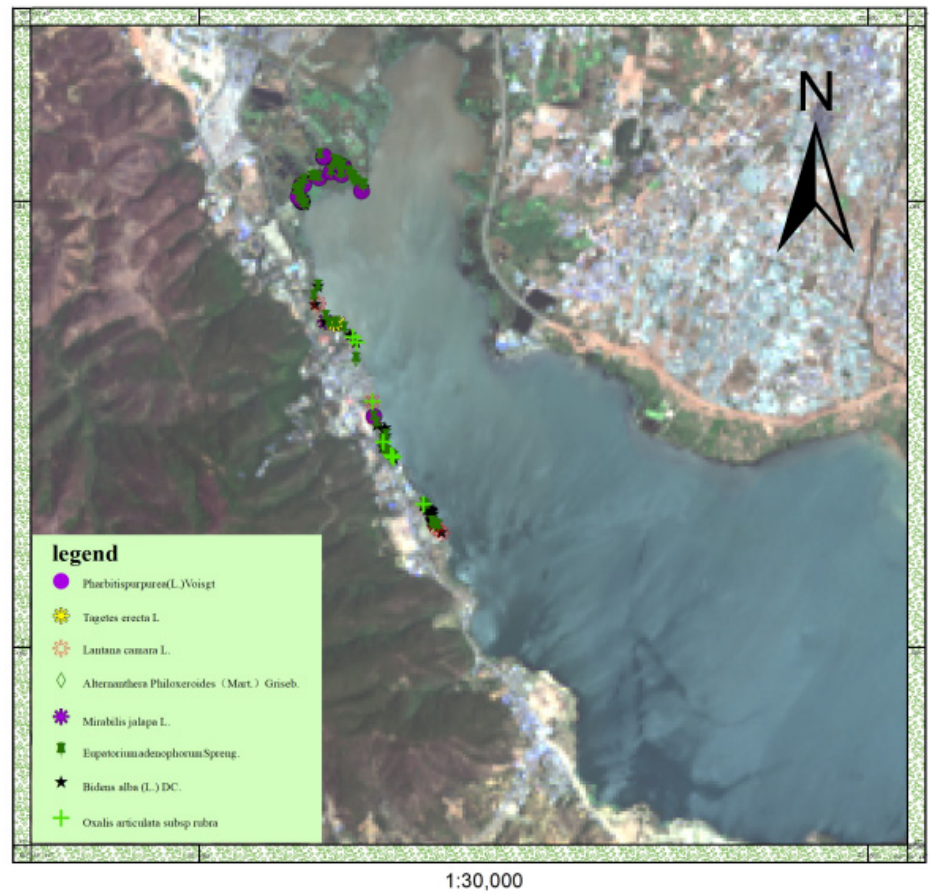

Fig.2. Map of the second investigation and distribution of invasive plants in Qionghai

\subsection{Trend changes}

The distribution of Eupatorium Adenophorum, Lantana camara, Alternanthera philoxeroides and Pharbitis purpurea (L.) Voisgt is the most widely in Qionghai Lake. They spread along the northwest and southeast of the investigation route. The number of Pharbitis purpurea (L.) Voisgt in winter is decreasing gradually. The number of Bidens alba(L.) DC and Oxalis corniculata L. is higher. They spread in the northwest and southeast. The distribution of Tagetes erecta $L$. is gradually expanding. The number of Mirabilis jalapa L. largely unchanged.

\section{Conclusion}

\subsection{The way which alien plants invade the Qionghai Sea}

Man-made introduction is a conscious and purposeful introduction of alien species.Man-made introduction plays an important role in the invasion of Qionghai by foreign plants. The purpose of introduction is mainly because plants have medicinal value, ornamental value, scientific research and so on. Unintentional introduction refers to the unintentional introduction of alien species through means of transport, cargo, human sons and animals. Such as Bidens alba(L.)DC. Natural invasion refers to the introduction of non-human causes.its pollen, seeds and reproductions through the wind, water flow, animal carrying, bird flight and other natural diffusion. It is this way that Eupatorium Adenophorum migrates. Differences in intrusion paths and intrusion times can lead to different intrusion effects.Some invasive plants may cross-invade in two or more ways. Cross-invasion and multiple invasions increase the likelihood of alien invasive plants spreading.

\subsection{Prevention and control measures for invasive plants}

Regular field surveys of invasive plants in Qionghai Wetlands. Get a comprehensive grasp of the existing invasive plant growth situation. Timely detection of invasions of new species. Comprehensive management of invasive plants with serious hazards such as direct artificial eradication, chemical prevention and removal, biological control. Pay close attention to the growth characteristics of newly invaded species. In the event of hazards to the growth and spread of other organisms, they are immediately controlled and removed to prevent diffusion. Establish and improve relevant laws and regulations according to the situation in Qionghai. Develop special countermeasures against species that are more harmful. Relevant departments and personnel who blindly introduce and illegally introduce alien species and cause serious damage to the ecological environment of Qionghai shall be investigated for administrative criminal responsibility in accordance with the law.

Staff monitor invasive plants in real time and regularly map the distribution of invasive plants. This determines the level of risk of diffusion for each period and pays attention to the higher level. The park takes preventive and control measures to reduce the harm.

\section{References}

1. Chen Kaiwei. Ecological hazards and countermeasures of invasive alien species in Bohai Wetlands, Xichang City, Sichuan Province. J. Journal of Jiangxi Institute of Education, 34(3):39-42(2013) 
2. Yang Hong. Investigation on the status of invasive alien species in Qionghai Wetlands and its Impact on Qionghai Wetlands. J. Mianyang Normal College Journal, 28(11):58-62(2009)

3. Liu Bingliang. Effect of tourism development on the spillover effect of plant at the edge of the landscape. J. Acta Ecologica Sinica, 5: 3653-3660(2018)

4. Quan Wei. Selection of model simulation of the wind-passing and diffusion process of foreign invasive plants. J. Chinese Journal Ecology. 37(9):2840-2848(2018)

5. Zhu Feng. The distribution characteristics of invasive plants in Yunnan and their influencing factors. J. Chinese Journal Ecology. 37(9): 2573-2580(2018)

6. Yang Zhaoqu. Investigation on the invasion of exotic plants in the Wetlands of Fengmen Bay. J. Journal Of Weed Science.36(2):10-15(2018) 